Revista de Economia Política, vol. 30, n 3 (119), pp. 473-490, julho-setembro/2010

\title{
Causa e efeito: contribuições de Marx para investigações sobre finanças e inovação
}

EDUARDO DA MOTTA E ALBUQUERQUE*

Marx has a method for the evaluation of patterns of interaction between finance and innovation. Two starting points of this method are the simultaneity of cause and effect and the identification of reciprocal effects between the monetary-financial dimension and the industrial-innovative dimension. This paper investigates this method firstly defining a dynamic concept of money. The connections between the monetary-financial dimension and the industrial-innovative dimension are examined through their historical and theoretical elements. Finally, the most important connections of this complex interaction are presented.

Keywords: finance; inovation; co-evolution; marx, method.

JEL Classification: B1; G2; O3.

"A conexão entre o sistema monetário
e a origem e o desenvolvimento da maquinaria
é tão estreita que não necessita demonstração"
(Georg Simmel, 1907, p. 197).

\section{INTRODUÇÃO}

A relação entre finanças e inovação é um tema importante, que a literatura econômica tem atribuído uma atenção crescente. Levine (1997) apresenta uma

\footnotetext{
* Centro de Desenvolvimento e Planejamento Regional de Minas Gerais da Universidade Federal de Minas Gerais - Cedeplar-UFMG. E-mail: albuquer@cedeplar.ufmg.br. Os estudos no grupo de pesquisa Economia Política Contemporânea, liderado pelo Prof. João Antonio de Paula, além das conversas, discussões e referências sugeridas por Frederico Jayme Junior, Marco Crocco, José Eisenberg, Hugo Eduardo da Gama Cerqueira, Cândido Guerra, Fernando Cardim, João Sicsú, Wilson Suzigan e Marcelo Pimenta Marques contribuíram para o desenvolvimento deste texto. Os comentários e sugestões de dois pareceristas anônimos da Revista de Economia Política contribuíram para aperfeiçoar esta versão do artigo. Os erros são de responsabilidade exclusiva do autor.
} 
resenha da literatura. Uma questão relevante é a natureza das conexões entre a dimensão monetário-financeira e a dimensão industrial-inovativa. Levine (1997), por exemplo, enfatiza o sentido da causalidade entre instituições financeiras e desenvolvimento das nações.

Herskovic (2007) sistematiza estatísticas que indicam uma correlação entre dados relativos à riqueza das nações (PIB per capita), produção científico-tecnológica (uma variável que combina patentes e artigos científicos produzidos pelos países) e a dimensão monetário-financeira (uma variável que combina o crédito gerado pelo setor bancário e a capitalização de mercado das empresas listadas nas bolsas de valores). O Gráfico 1 apresenta esses dados (cada ponto representa um país - estão no gráfico todos os países com produção científica e tecnológica e com bancos e bolsas de valores).

Gráfico 1: Logaritmo de PIB per capita (2003), TEC (variável que engloba a produção científica e tecnológica do período 1999-2003) e FIN (variável que engloba a dimensão dos bancos e das bolsas de valores, dados para 2003).

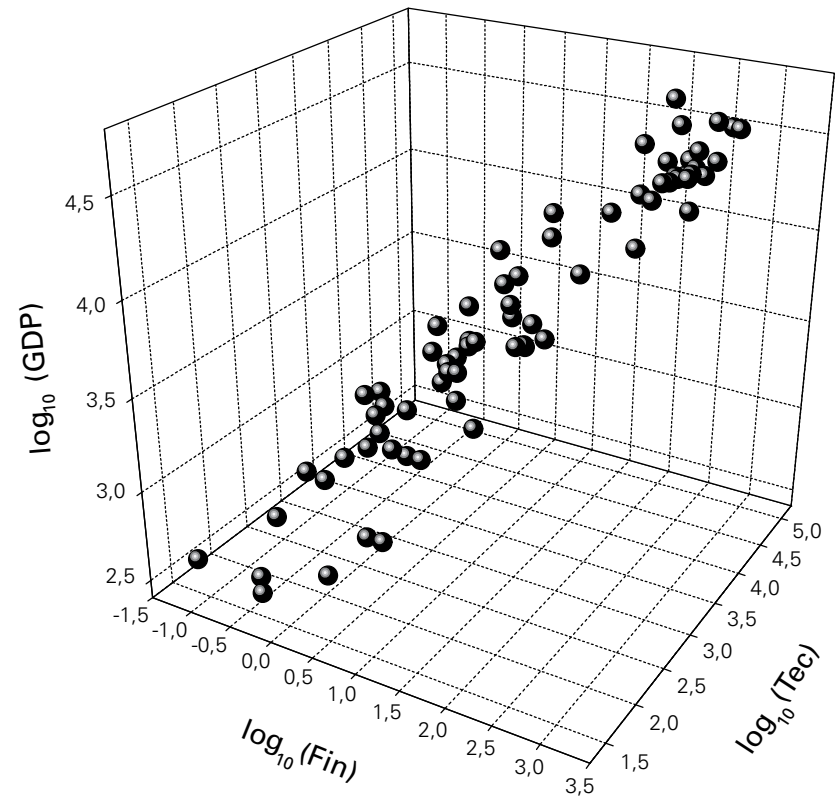

Fonte: Herskovic (2007)

O Gráfico 1 sugere uma articulação entre o estágio de construção dos sistemas financeiros, sistemas de inovação e riqueza das nações. Esses dados estimulam uma investigação teórica sobre eventuais mecanismos de efeitos recíprocos entre essas dimensões.

A simultaneidade entre causa e efeito e a identificação de efeitos recíprocos entre mudanças na dimensão monetário-financeira e na dimensão industrial-inovativa sintetizam um enfoque introdutório de Marx sobre o tema. Esse enfoque 
apresenta um padrão de causalidade e de dinâmica que pode dialogar com a literatura evolucionista a partir de conceitos como "co-evolução de instituições" (Nelson, 1995).

Nos últimos anos a elaboração evolucionária tem dedicado uma atenção crescente ao tema da articulação entre inovação e finanças. Esses trabalhos veem preencher uma lacuna importante, explicitamente reconhecida por O'Sullivan (2004). De certa forma, esses trabalhos fazem justiça a um autor muito apreciado pela elaboração evolucionista: o papel do sistema financeiro para a dinâmica inovativa é central na elaboração inicial de Schumpeter (1911), que define o "mercado monetário" como o "quartel-general" do sistema capitalista (p. 86). ${ }^{1}$

Entre os trabalhos que expressam essa preocupação teórica destacam-se O’Sullivan (2004), Chesnais $(2004,2006)$ e Perez (2002). Essas contribuições são importantes, mas algumas limitações podem ser indicadas: 1 ) uma definição pouco trabalhada do que seria o "capital financeiro" (especialmente em Perez, 2002); 2) uma excessiva clivagem/separação entre as duas dimensões, articulada com um certo impressionismo em relação à expansão financeira atual (identificado na análise de Chesnais); 3) uma certa subestimação das transformações institucionais que sofrem as instituições financeiras para dar conta da interação com a dimensão industrial-inovativa; 4) enfim, a falta de um quadro teórico consistente para captar as inter-relações entre a dimensão financeira e a dimensão industrial-inovativa.

Este artigo sugere que um diálogo com a elaboração de Marx enriqueceria esse esforço evolucionista, ao contribuir para a construção de um quadro teórico mais abrangente e consistente. ${ }^{2}$

\section{ELEMENTOS METODOLÓGICOS PRESENTES NA OBRA DE MARX}

A hipótese deste artigo sugere que a obra de Marx contém elementos metodológicos importantes para a construção de uma articulação dinâmica entre a dimensão monetário-financeira e a dimensão industrial-inovativa.

Um esclarecimento preliminar: a elaboração de Marx tem muito a aprender com estudos evolucionistas (Freeman, Nelson) e pós-keynesianos (Minsky, Chick). Eles investigam a inovação e a tecnologia (evolucionistas) e o dinheiro e as finanças (pós-keynesianos) no capitalismo dos séculos XX e XXI.

Através da compreensão dos contextos históricos distintos e das preocupações teóricas centrais diversas que deram origem a essas abordagens é possível o estabelecimento de alguns pontos de contato que permitam um diálogo teórico. Dife-

\footnotetext{
${ }^{1}$ A sistemática preocupação de Schumpeter com a questão financeira pode ser constatada em duas obras póstumas: History of Economic Analysis e Das Wesen des Geldes. Na primeira (Schumpeter, 1954) os temas relacionados ao dinheiro, articulações financeiras, desenvolvimento dos bancos na historia do pensamento econômico são avaliados cuidadosamente. Na segunda (Schumpeter, 1970), um desenvolvimento ambicioso de sua teoria sobre o dinheiro é apresentado.

${ }^{2}$ Este artigo pretende desenvolver alguns pontos apresentados inicialmente em Paula et al. (2001).
} 
rentes origens e focos temáticos ajudam esclarecer os pontos fortes e os pontos fracos de cada abordagem teórica. A consciência dessas características, somada à consciência de importantes diferenças teóricas, devem servir para organizar esse diálogo. Uma vez estabelecidos pontos de contato, é possível enriquecer a elaboração de Marx com toda a compreensão que a abordagem evolucionista oferece sobre a dinâmica tecnológica no capitalismo contemporâneo e que a abordagem pós-keynesiana oferece sobre a dinâmica financeira no mundo atual. Uma atualização da elaboração de Marx permite uma exploração mais completa dos elementos dinâmicos contidos em sua elaboração. Por outro lado, a riqueza teórica da elaboração de Marx poderia ajudar evolucionistas e pós-keynesianos a ir além de suas especializações mais notórias.

A importância e a necessidade desse diálogo para a elaboração de Marx ficam nítidas quando se considera o caráter inacabado de sua obra, especialmente em relação às questões monetárias e financeiras. Para tanto, as dificuldades de edição do terceiro volume de O Capital relatadas por Engels no seu prefácio de 1894 devem ser relembradas. Nesse relato, Engels é explícito ao afirmar que a maior dificuldade foi encontrada exatamente na Parte V ("a divisão do lucro em juros e ganho empresarial”). Krätke (2005), em um trabalho no qual relata investigações realizadas a partir de manuscritos ainda inéditos de Marx, desvenda como a questão monetário-financeira era uma das preocupações centrais de Marx após 1867. Notas de leitura e extratos produzidos em 1868-1869 e em 1878-1879 envolvem mais de 700 páginas sobre o tema. Numa palavra, a investigação não tinha se completado.

Por isso, seria particularmente rica uma leitura de Marx que busque captar os elementos de tensão em sua elaboração, focalizando assim nos elementos dinâmicos e nos potenciais desenvolvimentos presentes na sua exposição.

Um bom ponto de partida são duas referências básicas. A primeira, nos Grundrisse, sugere uma formulação de causalidade dinâmica, na medida em que mudanças em uma dimensão (industrial) podem ser causa e também efeito de mudanças na outra dimensão (monetário-financeira): nessa passagem Marx discute bancos, crédito e o processo de concentração de capital (pp. 122-123). A segunda, no terceiro volume de $\mathrm{O}$ Capital, sugere a existência de efeitos recíprocos entre as duas dimensões, na medida em que desenvolvimento em uma leva ao desenvolvimento em outra, e vice-versa (p. 612).

A sugestão de que Marx pode apresentar um método para lidar com essas duas dimensões é perfeitamente compatível com a abrangência de sua elaboração sobre o processo de produção capitalista.

O esquema sintetizado na fórmula D-M-D' pode ser lido como uma indicação da forte interligação e interdependência entre o dinheiro (e capital monetário) e o processo produtivo (capital industrial ou produtivo). É uma fórmula que condensa um conjunto de relações que serão desenvolvidas e explicitadas ao longo dos três volumes de O Capital (é importante lembrar que a fórmula D-M-D' é apresentada na Parte I do Volume I do livro).

Ao longo de O Capital a discussão da inter-relação entre o dinheiro e o pro- 
cesso produtivo vai transitando de um nível de abstração mais alto - a generalidade, o capital em geral, como no Volume I - para um nível menos abstrato - a singularidade, o conflito entre os vários capitais, como no Volume III. ${ }^{3}$ No volume III, as Partes IV e V apresentam divisões funcionais entre os vários capitais, com a discussão dos capitalistas comerciantes de dinheiro, dos capitalistas monetários e o desenvolvimento correspondente de instituições como crédito, bancos e as metamorfoses do dinheiro e de seu significado.

Quando se resgata a fórmula D-M-D' da vulgarização de “manuais de marxismo" abre-se a possibilidade de análise do capitalismo no qual há uma indissociabilidade entre dinheiro e produção. Afinal, na investigação de Marx é essencial a pergunta sobre "como o dinheiro se transforma em capital" (1867, pp. 268-269).

As articulações entre a dimensão monetário-financeira e a dimensão industrial-inovativa são construídas ao longo dos três volumes de O Capital. No primeiro volume Marx, ao tratar dos processos de centralização e concentração de capital (o processo de desenvolvimento da grande empresa, no linguajar mais tradicional da economia industrial), processos decisivos na dinâmica de acumulação de capital, explicita o papel das sociedades por ação como viabilizadoras dos investimentos necessários. $\mathrm{E}$ as ações são títulos, um exemplo de capital fictício, tema para desenvolvimento posterior (no terceiro volume). No segundo volume, ao tratar do processo de produção e circulação de capital, do processo como um todo, Marx indica sistematicamente o papel do sistema de crédito e do sistema bancário para promover o encurtamento do tempo de circulação e o barateamento dos custos de circulação e para acelerar a rotação de capital (ambos movimentos com forte impacto sobre a massa de lucros). No terceiro volume, a divisão funcional entre diferentes capitais é apresentada, e a contraposição entre o capitalista monetário e o capitalista produtivo é desenvolvida (em antecipação ao célebre esquema do segundo capítulo da Teoria do Desenvolvimento Econômico, de Schumpeter). Essa contraposição é cristalizada na divisão do lucro entre juros (a parte do capital monetário) e ganho empresarial (a parte do capitalista produtivo).

Essas anotações preliminares contribuem para explicitar o objetivo deste artigo: investigar os elementos mais importantes de um método elaborado por Marx para lidar com a inter-relação entre a dimensão monetário-financeira e a dimensão industrial-inovativa.

\section{UMA NOTA PRELIMINAR: UMA CONCEPÇÃO DINÂMICA DE DINHEIRO}

Um pressuposto de toda a elaboração de Marx é o caráter histórico do dinheiro e uma dinâmica específica às metamorfoses pelas quais passa o dinheiro ao

\footnotetext{
${ }^{3}$ Paula (2003) discute os diferentes níveis de abstração em O Capital.
} 
longo da história. Os elementos teóricos para essa dinâmica encontram-se em várias obras. Nos Grundrisse Marx menciona formas "inferiores" e "superiores" de dinheiro (p. 145), descrevendo como a função do dinheiro como "medida" antecede o aparecimento de sua função como "meio de troca" (p. 160) e o significado dos metais preciosos como uma "transição natural da primeira forma do dinheiro" (p. 166). Ainda nos Grundrisse há uma referência importante sobre o papel moeda e seu significado: "no curso do desenvolvimento o valor de troca do dinheiro pode mais uma vez existir separadamente de sua matéria, de sua substância, como no caso do papel moeda" (p. 167).

Através do raciocínio sobre formas superiores e formas inferiores de dinheiro, Marx nos Grundrisse chega à conexão com o capital, sugerindo o estabelecimento de uma nova fase com a emergência do modo de produção capitalista: "dinheiro como capital é um aspecto do dinheiro que vai além do seu simples caráter como dinheiro. Pode ser visto como a sua mais elevada realização... De qualquer forma, dinheiro como capital é distinto de dinheiro como dinheiro. Por outro lado, capital como dinheiro parece ser a regressão do capital a uma forma inferior" (1857-1858, pp. 250-251). A era do capital impõe ao dinheiro uma nova dinâmica, cujas características mais importantes Marx busca captar ao longo de O Capital. Essa nova dinâmica impõe ao dinheiro transformações qualitativas para aperfeiçoar, facilitar e multiplicar as possibilidades de sua transformação em capital. Historicamente é um processo complexo, cheio de experimentações, de eventos acidentais e aprendizado, que acontecimentos como a não convertibilidade da libra em ouro de 1797 a 1821 ilustram (Villar, 1974, pp. 314-319).

A percepção dessa dinâmica por Marx (a dinâmica do capital subjugando e impondo uma nova dinâmica ao dinheiro e suas formas) abre espaço para alguns pontos de contato com outras abordagens teóricas. Em primeiro lugar, uma articulação com a elaboração combinada de Simmel, Knapp e Keynes, na medida em que a transformação qualitativa no dinheiro em símbolo (na linguagem de Simmel) exige a entrada do Estado bancando o valor desse símbolo (Simmel, 1907, p. 184). ${ }^{4}$ As metamorfoses no dinheiro exigem a criação de novas instituições, novamente um processo histórico de longa duração e muita experimentação. Keynes, a partir de um novo contexto histórico e monetário, (1930, p. 4) afirma que "it is when this stage in the evolution of money has been reached that Knapp's chartalism - the doctrine that money is peculiarly a creation of the state - is fully realised".

Ao longo de O Capital identifica-se uma tensão na elaboração de Marx, que aponta as limitações da circulação metálica para o desenvolvimento do modo de produção capitalista: a produção capitalista seria impossível com a circulação meramente metálica. Essa passagem indica a produção de metais preciosos como uma barreira à produção capitalista (volume II, p. 420). Dessa forma, o desenvolvimento do crédito e do papel moeda é indispensável para a produção capitalista. No

\footnotetext{
4 "The concept of abstract value detached from any specific form - value that is not guaranteed by na objective quality but only by the state or the individual person ...” (Simmel, p. 184).
} 
capítulo sobre o dinheiro na Parte I do Volume I de O Capital, encontram-se todos os elementos impulsionadores do sistema de crédito e do papel moeda na história do modo de produção capitalista.

A leitura de Braudel contribui para indicar a permanente dinâmica para o que a literatura contemporânea chama de inovações financeiras. Braudel (1986) apresenta o contexto histórico da retomada da cunhagem de moedas em cidades-estado italianas (p. 95), ao mesmo tempo em que indica o surgimento de outras inovações como o cheque, a contabilidade das entradas duplas, os bancos, e seguros sem notários (p. 112), as operações de crédito dos comerciantes italianos nas feiras de Champagne (p. 96).

Simmel (1907) apresenta uma dinâmica singular do dinheiro que combina um declínio do "significado do dinheiro como substância" e um aumento do "significado do dinheiro como valor" (como "puro símbolo") (pp. 190-202).

Para compreender a grandeza e os limites da elaboração de Marx, é importante situá-lo historicamente. Aliás, Marx localizou historicamente os horizontes teóricos de Hume e Ricardo, em uma passagem célebre do Para a crítica da economia política: "o que as minas americanas significaram para Hume, as prensas de notas de Threadneedle Street significaram para Ricardo" (1859, p. 121). Cameron (1967) sintetiza em uma tabela (Tabela 2, p. 42) as mudanças quantitativas no estoque de dinheiro e de meios de pagamento na Inglaterra e País de Gales entre 1688 e 1913. Essa tabela mostra o progressivo declínio da moeda metálica e a correspondente ascensão do dinheiro criado por bancos (pp. 46-47): em 1688-89 dinheiro em espécie representava $83,3 \%$ do estoque monetário e em 1913 apenas $11,5 \%$. No tempo de Marx, em 1875, por exemplo, esse valor alcançou 19,2\%. A elaboração de Marx investiga essas mudanças e avalia a sua dinâmica histórica.

Essa observação inicial e os diálogos teóricos aí implícitos servem para questionar elaborações que situam Marx como um metalista ou como um autor que não foi capaz de superar uma visão do dinheiro-mercadoria. Anitra Nelson (1999) é um exemplo recente dessa visão e Krätke (2001) apresenta argumentos contrários. Em suma, uma interpretação de Marx como autor de uma elaboração dinâmica do dinheiro é um pressuposto para o conjunto da discussão deste artigo.

\section{ACUMULAÇÃO MONETÁRIA, BANCOS E CRÉDITO COMO PRECONDIÇÃO PARA O MODO DE PRODUÇÃO CAPITALISTA}

Para o deflagrar histórico do processo D-M-D' (nomeado por Marx nos Manuscritos Econômicos de 1861-1863 como dinheiro-em-processo, pp. 16-17, expressão também utilizada no primeiro volume de $O$ Capital, p. 256) a acumulação prévia de massas monetárias foi fundamental. Isso pode ser discutido a partir das notas de Marx sobre a usura e sua relação com a emergência do novo modo de produção. A importância histórica da usura deve-se ao fato dela, ao lado do capital mercantil, ter originado a formação de uma riqueza monetária independente da propriedade da terra (1894, pp. 732-733). Quando os meios de produção são 
fragmentados, a usura centraliza a riqueza monetária. Ao lado do papel de "arruinar os proprietários das antigas condições de trabalho", a usura forma uma riqueza monetária autônoma ao mesmo tempo que uma classe de mercadores (p. 745) e com esse "efeito duplo" a usura é uma "poderosa alavanca na formação das precondições para o capital industrial".

A identificação de "riqueza monetária autônoma" como uma precondição permite um novo ponto de diálogo com a elaboração de Braudel, em especial com a sua discussão das expansões financeiras. Braudel descreve como os recursos excedentes gerados no período histórico da hegemonia de Amsterdã migram para a Inglaterra. Braudel mostra como a Inglaterra era o destino dos capitais excedentes dos negociantes holandeses e como "o afluxo de dinheiro holandês deu fôlego ao crédito inglês" (1986, p. 240).

Por outro lado, a luta contra a usura, especialmente na Inglaterra no século XVIII, é vista por Marx como tentativa para submeter o capital portador de juros ao capital industrial. O desenvolvimento do crédito e de suas instituições, incluindo os bancos modernos, é analisado por Marx como esforços de novos mercadores e comerciantes para se emanciparem da usura (pp. 736-740). Marx identifica, por um lado, "a demanda para a subjugação do capital portador de juros ao capital industrial" simplesmente como precursora (Vorläufer) das "criações orgânicas que essas condições da produção capitalista produzem na forma do moderno sistema bancário" (p. 738). Por outro lado, esse "moderno sistema bancário" rouba do capital usurário o seu monopólio (pois concentra todos as reservas monetárias e as coloca no mercado monetário) e restringe o monopólio dos metais preciosos através da criação de dinheiro de crédito (p. 738). ${ }^{5}$

Adiante, Marx indica que o "caráter social do capital”, é mediado e completamente realizado apenas com o "desenvolvimento pleno do sistema bancário e de crédito" (p. 742). Desde o início do modo de produção capitalista, esse desenvolvimento institucional possibilita a emergência de uma divisão mais complexa entre os diversos capitais, com uma divisão de trabalho funcional entre eles.

Outro elemento importante nas precondições para o desenvolvimento capitalista é a dívida pública $(1867$, p. 918) — "uma das alavancas mais poderosas da acumulação primitiva”. Braudel descreve a relação entre a dívida pública e o Banco da Inglaterra (1986, pp. 347-350) e entre o sistema bancário inglês e o Banco da Inglaterra (1986, pp. 558-565). O resultado é uma avaliação da relação entre finanças e o capitalismo, pois para Braudel na Inglaterra "houve mesmo uma revolução financeira que correu misturada com a industrialização do país, que se não a provocou, pelo menos a acompanhou e até mesmo a tornou possível” (p. 559).

O papel da dívida pública para o sistema bancário inglês leva a uma observação importante: o capital fictício, segundo o conceito de Marx, faz parte dos me-

\footnotetext{
${ }^{5}$ Essa passagem contribui para esclarecer como desenvolvimentos institucionais influem sobre a natureza do dinheiro e enriquece a discussão sumária da segunda seção.
} 
canismos da acumulação primitiva (títulos da dívida pública constituem um exemplo de capital fictício).

Assim, massas monetárias independentes, bancos, crédito, dívida pública e capital fictício já estão presentes na origem do modo de produção capitalista, constituindo precondições e pressupostos para o seu desenvolvimento. Os desenvolvimentos institucionais sumarizados nesta seção ilustram os processos históricos para a deflagração do esquema D-M-D’. É razoável supor que esses desenvolvimentos foram, por um lado, causa dos desenvolvimentos do capitalismo industrial posterior e, por outro lado, consequência de demandas e pressões advindas desses desenvolvimentos. A relação de causa e efeito opera desde o início do desenvolvimento capitalista.

\section{ELEMENTOS PARA A CONSTRUÇÃO DE UMA INTERAÇÃO COMPLEXA}

Simmel (1907) associa o desenvolvimento da economia monetária e o crescimento de habilidades intelectuais (p. 152). Sohn-Rethel $(1978$, p. 65) apresenta uma associação entre o desenvolvimento do dinheiro na Grécia Antiga - mais especificamente o "abstract material of money" - e a elaboração de Parmênides. ${ }^{6}$ Nessa mesma linha, Seaford (2004) associa a emergência da cosmologia filosófica na Grécia Antiga ao pioneirismo na cunhagem da moeda (um expressivo salto qualitativo na história do dinheiro), propondo uma relação direta entre o dinheiro em uma nova forma e novas habilidades necessárias do raciocínio abstrato.

Em um comentário sobre a elaboração de Seaford, o Prof. Marcelo Pimenta Marques (Departamento de Filosofia, UFMG) sugere um conjunto mais amplo de fatores como criadores das condições para a emergência do pensamento grego (escrita, condições políticas, influência da democracia, desenvolvimento de profissões etc.). Com essa ressalva, nesse contexto mais amplo faria sentido discutir o papel do dinheiro para a experiência do pensamento.

Essa relação entre dinheiro e pensamento científico extrapola esse momento inicial. Como ilustração, vale mencionar dois episódios da história da ciência. O primeiro refere-se à descoberta por Arquimedes da densidade específica dos corpos (Taton, 1961, p. 385), que foi motivada por um problema relativo ao conteúdo de ouro de coroa uma encomendada por um tirano de Siracusa. O segundo, uma outra articulação, talvez menos direta, entre dinheiro e desenvolvimento científico, pode ser sugerido a partir das reavaliações da contribuição da alquimia para o desenvolvimento científico moderno: pelo menos o aperfeiçoamento de práticas de laboratório pode ser mencionado como uma das consequências das práticas alquimistas de Isaac Newton (Gabbey, 1990, pp. 252-258).

Outra característica que extrapola o período clássico é um padrão de associa-

\footnotetext{
${ }^{6}$ Galvan (2001), a partir da obra de Sohn-Rethel, destaca a relação entre sistema monetário e as primeiras sistematizações da ciência como parte do legado da Grécia clássica.
} 
ção geográfica e temporal da liderança nas esferas monetária e tecnológico-científica: a liderança da Grécia clássica nessas esferas é reconhecida, inaugurando esse padrão. Essa associação persiste ao longo da história e é captada por Braudel (1986). Basta acompanhar a sequência de centros hegemônicos e identificar neles a liderança nas duas dimensões: Veneza (1378-1498), Gênova (1557-1627), Amsterdã (1627-1773/1783), Londres (1773) e Nova York que substitui Londres no início do século XX.

Possivelmente uma lógica que fundamenta tal associação vem discutida desde os Grundrisse, nos quais Marx indica uma relação entre o dinheiro, a divisão de trabalho e o seu aperfeiçoamento. O dinheiro e as relações monetárias desenvolvem-se em sintonia com a divisão de trabalho, isto é, diz Marx, com o crescente caráter social da produção $(1857-1858$, p. 146). Na medida em que cresce o caráter social da produção, portanto a divisão do trabalho, também cresce o "poder do dinheiro" (p. 146). Mais adiante, Marx especifica ainda mais essa relação, detalhando a sua gênese, ao afirmar que "o dinheiro oferece a possibilidade de uma divisão absoluta do trabalho" (p. 200). Evidentemente esse ponto é derivado de Adam Smith, que no Capítulo IV, Livro I, ao tratar da "Origem e uso do dinheiro", aponta o papel da divisão de trabalho (Smith, 1776, pp. 126-131) nessa gênese.

Essa relação entre dinheiro e divisão de trabalho pode ser traduzida como uma relação entre o dinheiro (e sistema monetário) e melhoras na produtividade, logo, progresso técnico. A primeira forma de progresso técnico exposta pela nascente economia política é exatamente a divisão do trabalho, exemplificada na descrição e análise de Adam Smith sobre a manufatura de alfinetes.

$\mathrm{O}$ percurso da exposição de Marx na Parte IV do primeiro volume de $\mathrm{O} \mathrm{Ca}$ pital, na qual a dinâmica do progresso técnico está exposta ("o impulso permanente do capital pela ampliação da produtividade do trabalho", pp. 436-437), absorve essa elaboração de Adam Smith, ao mostrar a transição da cooperação para a manufatura e da manufatura para a fábrica e a "grande indústria", integrando-a em uma perspectiva histórica mais ampla. Dessa forma, há um elemento genético na relação entre dinheiro e divisão de trabalho, que posteriormente passará por um conjunto de mutações e transformações, apresentado por Marx ao longo de $O$ Capital.

Nos três volumes de O Capital a questão do dinheiro, de suas metamorfoses, do desenvolvimento do sistema monetário e do sistema de crédito, além de suas relações com a dimensão industrial-inovativa, vai se desdobrando e acompanhando os diversos níveis de abstração que Marx adota. É possível insistir que Marx, em cada um dos volumes, deixa claro as articulações entre as dimensões monetário-financeira e industrial-inovativa.

O sistema bancário e o sistema de crédito são construções institucionais para impedir a permanência do dinheiro na ociosidade (ou seja, rompendo bloqueios à sua permanente transformação em capital). O que Simmel (1907, p. 212) corretamente trata como a "restlessness of money" pressupõe essas bases institucionais apresentadas pela análise de Marx. Por isso, já na Parte I do primeiro volume de O Capital, o dinheiro aparece como passível de um conjunto de metamorfoses, de 
mudanças funcionais, de potencial evolutivo em direção ao papel moeda, à sofisticação do crédito e a novas formas de capital fictício.

$\mathrm{Na}$ Parte V (Capítulo 27) Marx sintetiza a função do crédito na sociedade capitalista. Localizado após a exposição da divisão funcional entre os vários capitais, Marx pode mostrar como o desenvolvimento das instituições de crédito (o crédito e seus instrumentos são desenvolvimentos do dinheiro como meio de pagamento) eleva as possibilidades de acumulação de capital. Nesse ponto, Marx já discute a emergência das sociedades por ações e o papel das bolsas de valores, então em fase de transição para um papel maior nas economias capitalistas. Mas os elementos dinâmicos essenciais lá estão, em especial os impactos do desenvolvimento do crédito sobre a substituição do dinheiro metálico por papel moeda (1894, p. 567). O sistema de crédito é reconhecido explicitamente como impulsionador do desenvolvimento material das forças produtivas e da criação do mercado mundial (1894, p. 572). Esse sentido de causalidade é depreendido do comentário de Marx sobre ferrovias e centralização de capitais, cujo desenvolvimento foi acelerado pelas sociedades por ação $(1867$, p. 780$){ }^{7}$

O significado do sistema de crédito no sistema capitalista é uma antiga preocupação de Marx, certamente alimentada pela forma como os socialistas proudhonianos abordavam o tema. O tema do primeiro capítulo dos Grundrisse é o dinheiro e esse capítulo é iniciado por uma leitura crítica de um livro sobre bancos de um autor proudhoniano (Alfred Darimon). Nessa crítica, que se relaciona a todo um esforço de pesquisa e investigação de Marx sobre o dinheiro, as posições de socialistas em relação ao moderno sistema de crédito são avaliadas detalhadamente (o tema reaparece no terceiro volume de O Capital, no qual os saint-simonianos são o objeto principal da crítica). Nessas reflexões, Marx sugere uma certa unilateralidade nas análises de Darimon e outros sobre o papel do crédito na evolução do sistema capitalista. Essa unilateralidade teria importantes implicações políticas, pois dessa forma propostas de transformação limitadas à esfera da circulação seriam suficientes para superar o sistema capitalista (daí as propostas proudhonianas de crédito gratuito, substituição do dinheiro por bônus de trabalho etc.). Marx, ao criticar essa unilateralidade, afirma que "as modernas instituições de crédito seriam tanto uma causa como um efeito da concentração de capital” (p. 122).

Nas pesquisas e elaborações realizadas após os Grundrisse Marx mantêm esse padrão de relação entre as duas dimensões. No terceiro volume de O Capital, no primeiro capítulo sobre "capital monetário e capital real", Marx discute as relações entre crédito comercial e a produção em grande escala para mercados distantes, anotando que o crédito é indispensável aqui. Na sequência do raciocínio, Marx novamente sugere a existência de efeitos recíprocos entre crédito e indústria: “...crédito que cresce em volume com o crescimento do volume da produção e cresce em duração com o aumento da distância dos mercados". Daí, "um efeito recíproco tem lugar aqui. $\mathrm{O}$ desenvolvimento do processo de produção expande o

${ }^{7}$ Coutinho (1997, pp. 135 e 184) chama a atenção para essa passagem. 
crédito enquanto o crédito por sua vez leva a uma expansão de operações industriais e comerciais" (1894, p. 612).

Entretanto, essas relações de causa e efeito e de efeitos recíprocos não são relações lineares e sem crises.

\section{AS CONEXÕES MAIS IMPORTANTES NESSA INTERAÇÃO COMPLEXA}

A identificação de bancos e sistema de crédito como pressupostos para o desenvolvimento inicial do modo de produção capitalista articula-se necessariamente com a compreensão do desenvolvimento da divisão funcional entre os vários capitais, com a especialização de capitalistas no comércio de mercadorias e no comércio de dinheiro e a emergência de capitalistas monetários. Essa divisão funcional é cristalizada na diferenciação entre juros e lucro empresarial. A divisão funcional e a especialização daí derivada abrem uma nova dinâmica na relação entre os vários capitais. Por exemplo, a emergência de dividendos como uma forma específica de remuneração (de ações), uma contribuição teórica de Hilferding, ilustra essa dinâmica histórica. Dinâmica cada vez mais complexa e multifacetada, em desenvolvimento até hoje.

Esse caráter multifacetado nas relações de cause e efeito e de efeitos recíprocos pode ser mais detalhadamente investigado através de uma discussão de pelo menos cinco conexões entre a dimensões monetário-financeira e a industrial-inovativa.

Uma primeira conexão articula a expansão da produção material com a expansão da acumulação monetária. Ela é apontada por Marx na sua discussão nos capítulos sobre o capital monetário e o capital real, os capítulos 30 a 32, Parte V (é importante lembrar que, segundo Engels em seu prefácio, é com o capítulo 30 que a dificuldade de edição realmente começa). O capítulo 32 abre-se com uma referência à "massiva soma de dinheiro que [...] é o resultado da escala massiva do processo de reprodução". Vale repetir: o processo de produção material gera enormes massas monetárias. Essas massas monetárias devem ser retransformadas em capital. Essas massas monetárias em expansão implicam na expansão dos capitalistas monetários. Adiante há uma passagem, importante para o raciocínio deste artigo, na qual Marx explica que "na medida em que a riqueza material aumenta, a classe de capitalistas monetários cresce. Por um lado, há um aumento no número e na riqueza de capitalistas que se retiram (zurückziehenden Kapitalisten), os rentiers. Por outro lado, o sistema de crédito deve se desenvolver mais, o que significa um crescimento no número de banqueiros, emprestadores de dinheiro, financistas etc. Com a expansão do capital monetário disponível, também se expande o volume dos papéis portadores de juros, os títulos do governo, as ações etc.” (1894, pp. 642-643).

Essa conexão é explorada por Arrighi (1994) na sua elaboração sobre "ciclos sistêmicos de acumulação": fases de expansão material são sucedidas por fases de expansão financeira, em uma generalização do esquema D-M-D' para além dos circuitos mais específicos do capital. Arrighi se inspira em Braudel (1986), que 
apresenta os movimentos históricos entre expansões materiais e expansões financeiras. Essa associação e esse encadeamento temporal entre as expansões materiais e as expansões financeiras são importantes contribuições de Arrighi e Braudel ao debate contemporâneo, em especial para contextualizar as elaborações sobre a emergência de "regimes de acumulação financeira", pois as expansões financeiras seriam um fenômeno histórico mais geral e recorrente.

Dessa forma, é necessário compreender a inevitabilidade da acumulação de massas monetárias como resultado de fases de prosperidade industrial-produtiva.

Uma segunda conexão articula a expansão monetária com novos empreendimentos. Essa expansão também pode ser consequência do crescimento do sistema bancário (1894, p. 619). Ainda nos limites dos capítulos sobre "capital monetário e capital real”, Marx discute questões referentes à dinâmica cíclica (pp. 619-620), indicando uma fase de prosperidade na qual, apesar do aumento da demanda por capital de empréstimo, a taxa de juros não subiria em função das condições de oferta de recursos monetários. Esse seria um momento no qual inúmeros investidores industriais poderiam operar sem capital de reserva e apenas com base em dinheiro de crédito. Momento no qual, prossegue Marx, haveria uma "grande expansão de capital fixo em todas as formas" e a "abertura de um grande número de novas empresas" (pp. 619-620).

Por isso, essa segunda conexão indica a expansão monetária contribuindo para novos investimentos e, portanto, para nova expansão material.

Uma terceira conexão articula uma dinâmica entre mudanças quantitativas e qualitativas. A acumulação de massas monetárias crescentes e a maior disseminação dos mecanismos de crédito abrem espaço para inovações institucionais na esfera monetário-financeira. Ainda na Parte IV do terceiro volume, Marx indica uma dinâmica de duplo aperfeiçoamento da divisão de trabalho. Por um lado, há a especialização de funções entre os capitais, com a emergência de um capital comercial de dinheiro e de uma função específica de capital monetário, como um ramo especial de negócios. Por outro lado, há um aperfeiçoamento da divisão de trabalho no interior desse ramo especial de negócios. Trata-se de um "desenvolvimento entre vários ramos independentes uns dos outros e de um desenvolvimento dos locais de trabalho no interior desses ramos (escritórios grandes, numerosos contadores e caixas, uma divisão de trabalho altamente desenvolvida). Pagamento e recebimento de dinheiro, acerto dos balanços, manutenção de contas correntes, armazenamento de dinheiro etc. [...] transformam o capital adiantado nessas funções em capital de comércio de dinheiro" (p. 433).

O desenvolvimento posterior do sistema bancário, o permanente aperfeiçoamento da divisão de trabalho nos dois aspectos indicados por Marx (intersetorial, entre os diversos capitais e, intrassetorial, no interior do capital monetário, bancário e posteriormente financeiro) tem a sua dinâmica inicial apontada nessas passagens.

A contextualização histórica da elaboração de Marx e a ênfase nos elementos dinâmicos até aqui apontados permitem diálogos com elaborações que investigam a história dessas mudanças institucionais. Grosso modo, Marx está discutindo e investigando os períodos iniciais do sistema bancário, um período que antecede, 
por exemplo, inovações institucionais como o moderno Banco Central. Marx investiga o que Victoria Chick (1986) consideraria como os estágios 1 a 3 da evolução do sistema bancário. Por sua vez, a descrição de Chick sobre o aprendizado e a evolução institucional do sistema bancário indica a multiplicação de possibilidades de financiamento da acumulação capitalista surgidas ao longo do século XX. Multiplicação de possibilidades que tem relação com a ruptura de limites inelásticos oferecidos pela circulação metálica - e mesmo pelo padrão ouro - e o aparecimento de novas fontes para a acumulação de capital como a capacidade de criação de meios de pagamento pelo sistema bancário. Essas novas fontes para a acumulação de capital estão relacionadas às fases 4 e 5 do esquema de Chick, fases que significam uma mudança qualitativa no caráter do dinheiro, certamente facilitando em muito a sua transformação em capital.

Um outro exemplo, o desenvolvimento do venture capital — tão importante no final do século XX para o desenvolvimento de novas empresas relacionadas a novas tecnologias nos Estados Unidos (Gompers \& Lerner, 1999) — só pode ser compreendido como resultante da acumulação monetária e financeira alcançada naquele país. A divisão de trabalho no interior do setor financeiro possibilitou um novo desenvolvimento institucional e a emergência de uma forma de financiamento que conecta diretamente recursos financeiros e inovação.

Uma quarta conexão envolve ainda a relação entre mudanças qualitativas e quantitativas, mas em um sentido inverso ao do anterior. A ampliação da escala da produção, a maior importância dos investimentos em capital fixo (a tendência histórica ao crescimento da composição orgânica do capital) determina à dimensão industrial-inovativa novas demandas sobre o capital monetário e seu ramo especial de negócios. Para a realização de investimentos maiores, novas instituições são necessárias. Certamente viabilizados pela dinâmica exposta na terceira conexão acima, empreendimentos como ferrovias exigem/estimulam o aperfeiçoamento de sociedades por ações no século XIX. Essas por sua vez, contribuem para o aperfeiçoamento (novamente, mudanças quantitativas e qualitativas) de bolsas de valores - instituições para a "mobilização de capital", nos termos de Hilferding —, cujo amadurecimento contribui para novos saltos nos processos de centralização e concentração de capital. Essas articulações podem ser acompanhadas pela história de Wall Street e pela emergência das sociedades anônimas nos Estados Unidos no final do século XIX e início do século XX (Myers, 1931; Chandler, 1977; Geisst, 2004). Como Minsky (1986, p. 317) coloca, um mercado de títulos e de ações é um "complemento necessário" para a sociedade anônima como forma de organizar negócios.

Um painel histórico mais abrangente contribui para uma melhor percepção dessa dinâmica de transformações mutuamente determinadas. Freeman \& Perez (1988) oferecem um esquema que contribui para sumarizar essa relação dinâmica e as mutações que se processam nas duas esferas. Entre as características principais das diversas ondas longas, Freeman $\&$ Perez apresentam um roteiro relativo à organização das firmas. Nesse roteiro indicam como, na primeira onda longa, as firmas pequenas e os empresários dispunham de sua riqueza individua e tinham acesso a capital local. Na segunda onda longa as firmas, já um pouco maiores, 
contavam com sociedades por ações; na terceira onda longa, a emergência da grande empresa estava associada à concentração das atividades bancárias e ao capital financeiro; na quarta onda longa, a difusão das multinacionais implica no papel dos investimentos diretos no estrangeiro e, na quinta onda longa, há referência a estruturas como mercados de capitais internos às grandes corporações. No geral, Freeman \& Perez sugerem uma necessária co-evolução entre as duas dimensões, embora não a desenvolvam.

Finalmente, a conexão entre as duas dimensões está longe de ser simétrica, equilibrada e destituída de conflitos. Por um lado há as crises, por outro há disputas entre os diversos capitais (industrial, monetário, financeiro, comercial). As fases de expansão financeira que se repetem na história, como formulam Braudel e Arrighi, podem ser uma expressão singular desse ponto.

Em relação às crises, Marx destaca o papel contraditório que o crédito desempenha para a dinâmica capitalista. Se, por um lado, o crédito garante a fluidez do processo de produção e multiplica as oportunidades do processo de acumulação de capital, por outro lado abre novas possibilidades de irrupção de crises, ampliando a instabilidade do sistema. Novos desenvolvimentos levam necessariamente a novas fontes de instabilidade: um exemplo é o papel maior das bolsas de valores na estrutura financeira do capitalismo e a emergência da especulação com ações (mercado secundário) como uma nova fonte de crises, conforme analisa Hilferding. Esses desenvolvimentos combinados preparam o campo para o que Keynes, em um cenário institucional distinto, formula como dois circuitos distintos, mas relacionados: a circulação industrial e a circulação financeira (1930, p. 217).

Nesse sentido, a elaboração de Marx pode dialogar com a de Minsky (1986), que desde outro referencial teórico afirma ser a estrutura financeira "causa tanto da adaptabilidade como da instabilidade do capitalismo" (p. 175). A percepção de Marx acerca dessa instabilidade potencial pode contribui para entender a origem de inovações institucionais como o Banco Central e o New Deal (com suas medidas sobre regulação bancária e do mercado acionário), tão importantes para responder às consequências das novas fontes de instabilidade (ou, de forma mais geral e mais atual, há toda uma dinâmica que relaciona inovações financeiras e novas necessidades de regulação). De certa forma, essas notas sobre crises podem dialogar com a elaboração de Freeman \& Perez (1988) acerca dos "encaixes" e "desencaixes" entre instituições nos processos de co-evolução implícitos nas transformações estruturais do desenvolvimento capitalista. Freeman \& Perez sugerem a existência de crises estruturais de ajustamento nas transições entre diferentes ondas longas.

Outra fonte de conflitos é a disputa entre os vários capitais por sua remuneração. Essas disputas são investigadas no Volume III, onde Marx está no nível dos diversos capitais (os inúmeros capitalistas industriais, os capitalistas comerciais, os capitalistas monetários, os proprietários de terra etc). Esses diversos capitais disputam a maior participação possível na massa de lucros gerados pelo processo de produção e reprodução de capital. Uma disputa importante, detalhadamente descrita por Marx, é a divisão entre juros e ganho empresarial, a disputa ente o capitalista monetário e o capitalista industrial ativo. Essa disputa, na medida em que 
há o crescimento e a sofisticação tanto do lado industrial como do lado monetário-financeiro, vai se tornando mais complexa e envolvendo um número maior de atores (acionistas, banqueiros, industriais, comerciantes, distribuidores, etc. etc.), maior número de títulos e papéis negociáveis e o contínuo surgimento de novas instituições. Desenvolvimento que chega aos modernos fundos de pensão e de investimento, ao peso das instituições de seguro, quadro institucional mapeado por Chesnais $(2004,2006)$.

\section{COMENTÁRIOS FINAIS}

O padrão de causalidade sugerido neste artigo (simultaneidade entre causa e efeito, efeitos recíprocos) é uma introdução à vasta contribuição que a obra de Marx pode oferecer para a compreensão do relacionamento entre as mudanças nas dimensões monetário-financeira e industrial-inovativa.

O ponto inicial é a identificação de um método para tratar desse relacionamento. Esse método, além das relações básicas de causalidade, envolve a identificação do entrelaçamento entre as duas dimensões, um padrão de crescimento quantitativo e qualitativo que são justapostos, os impactos da maior disponibilidade de recursos sobre as possibilidades de investimentos, a repercussão da sofisticação da divisão de trabalho externa (entre os vários capitais) e interna (ao capital monetário) sobre os mecanismos de acumulação, os impactos reversos das demandas dos resultados dos processos de concentração e centralização de capital sobre o setor monetário-financeiro e, finalmente, o caráter conflituoso e pleno de potencial de crises apresentado por essas mudanças quantitativas e qualitativas ao longo do tempo.

A argumentação deste artigo enfatizou a natureza histórica e intertemporal das relações entre as duas dimensões, sumarizadas nos comentários sobre as crises estruturais de ajustamento durante as transições de ondas longas. Nesses comentários finais um outro aspecto pode ser focalizado. O Gráfico 1, apresentado na introdução, sintetizou estatísticas que sugerem uma articulação entre o estágio de construção dos sistemas financeiros, sistemas de inovação e o nível de desenvolvimento dos países. Essas estatísticas sugerem um próximo passo de uma agenda de pesquisa sobre finanças e inovação: a investigação de padrões de coevolução entre as duas dimensões entre diferentes estágios de desenvolvimento. Nessa investigação, um objetivo seria a identificar a forma particular tanto da simultaneidade entre causa e efeito como da dinâmica de efeitos recíprocos em processos de superação do atraso econômico.

\section{REFERÊNCIAS BIBLIOGRÁFICAS}

ARRIGHI, G. (1994) O longo século XX: dinheiro, poder e as origens do nosso tempo.Rio de Janeiro/ São Paulo: Contraponto/Unesp (1996).

BRAUDEL, F. (1986). Civilização material, economia e capitalismo: séculos XV-XVIII. São Paulo: Martins Fontes, Vol 3: O tempo do mundo (1996). 
CAMERON, R.; CRISP, O.; PATRICK, H.; TILLY, R. (1967) Banking in the early stages of industrialization. New York: Oxford University.

CHANDLER JR., A. (1977). The Visible Hand - The Managerial Revolution in America Business. London: The Belknap Press of Harvard University Press.

CHESNAIS, F. (org.) (2004) La finance mondialisée: racines sociales et politiques, configuration, conséquences.

CHESNAIS, F. (2006) La preeminence de la finance au sein du 'capital in general', le capital ficitif et le mouvement contemporain de mondialisation du capital. In: BRUNHOFF, S.; CHESNAIS, F.; DUMÉIL, G.; LÉVY, D; HUSSON, M. (orgs) La finance capitaliste. Paris, PUF, pp. 65-130.

CHICK, V. (1986) The evolution of the banking system and the theory of saving, investment and interest. In: CHICK, V. On money, method and Keynes. New York: St. Martin's Press, pp. 193-205 (1992).

COUTINHO, M. (1997) Marx: notas sobre a teoria do capital. São Paulo: Editora Hucitec.

FREEMAN, C.; PEREZ, C. (1988) Structural crisis of ajustment: business cycles and investment behaviour. In: DOSI, G.; FREEMAN, C.; NELSON, R.; et al. (eds). Technical change and economic theory. London: Pinter, pp. 38-66.

GABBEY, A. (1990) Newton and natural philosophy. In: COLBY, R. C.; CANTOR, G. N.; CHRISTIE, J. R.; HODGE, M. J. Companion to the history of modern science. London: Routledge, pp. 243-263.

GALVAN, C. (2001) Moeda e ciência: ensaios sobre a teoria de Sohn-Rethel. Recife: Centro de Estudos e Pesquisas Josué de Castro.

GEISST, C. R. (2004) Wall Street: a history. Oxford: Oxford University Press.

GOMPERS, P.; LERNER, J. (1999) The venture capital cycle. Cambridge, Mass.: The MIT Press.

HERSKOVIC, B. (2007) Efeitos recíprocos entre crédito e inovação. Belo Horizonte: FACE-UFMG (Monografia de conclusão de curso).

HILFERDING, R.(1910). Finance capital: a study of the latest phase of capitalist development. London, Boston, Melbourne and Henley: Routledge \& Kegan Paul 1981.

KEYNES, J. M. (1930) A treatise on money. The Collected Writings of John Maynard Keynes, vol. V. London: Macmillan (1971)

KNAPP, G. F. (1905) The state theory of money. San Diego: Simon Publications (1924)

KRÄTKE, M. (2001) Geld, Kredit und verrückte Formem. MEGA-Studien, n. 1, pp- 64-99.

KRÄTKE, M. (2005) Le dernier Marx et le Capital. Actuel Marx, n. 37, pp. 145-160.

LEVINE, R. (1997) Financial development and economic growth: views and agenda. Journal of Economic Literature, v. XXXV, pp. 688-726.

MARX, K (1867). Capital, Volume I. London: Penguin Books (1976).

MARX, K (1885). Capital, Volume II. London: Penguin Books (1978).

MARX, K (1894). Capital, Volume III. London: Penguin Books (1981).

MARX, K. (1857-58) Grundrisse. London: Penguin Books (1973).

MARX, K. (1859) Para a crítica da economia política. In: MARX. São Paulo: Abril Cultural, pp. 3-113 (1982).

MINSKY, H. P. (1986) Stabilizing an unstable economy. New Haven: Yale University Press.

MYERS, M. (1931) The New York money market. Vol I: Origins and Development. New York: Columbia University.

NELSON, A. (1999) Marx's concept of money: the god of commodities. London/New York: Routledge.

NELSON, R. (1995). Recent Evolutionary Theorizing About Economic Change. Journal of Economic Literature, Vol. XXXIII, March 1995, pp.48-90.

O'SULLIVAN, M. (2004) Finance and innovation. In: FAGERBERG, J.; MOWERY, D.; NELSON, R. Oxford handbook on innovation. Oxford: Oxford.

PAULA, J. A. (2003) Aparência e realidade capitalista: o lugar da concorrência na dinâmica do capital. Estudos Econômicos, v. 33, n. 1, p. 115-142.

PAULA, J. A.; CERQUEIRA, H. E.; ALBUQUERQUE, E. (2001) Finance and industrial evolution: 
introductory notes on a key relationship for the capitalist accumulation. Economica, v. 3, n. 1 . pp. 5-34.

PEREZ, C. (2002) Technological revolutions and financial capital. Cheltenhm: Edward Elgar.

SCHUMPETER, J. (1911) A teoria do desenvolvimento econômico. São Paulo: Nova Cultural (1985).

SCHUMPETER, J. (1954) History of Economic Analysis. London: Allen \& Unwin (1986)

SCHUMPETER, J. (1970) Théorie de la monnaie et de la banque. (2 vol) Paris: L'Harmattan (2005).

SEAFORD, R. (2004) Money and the early Greek mind. Cambridge: Cambridge University Press.

SIMMEL, G. (1907) The philosophy of money. London: Routledge. 3rd edition (2004)

SMITH, A. (1776) A Riqueza das Nações: investigação sobre sua natureza e suas causas. trad. port., São Paulo: Abril Cultural, 1983.

SOHN-RETHEL, A. (1978) Intelectual and manual labour: a critique of epistomology. London: The MacMillan Press.

TATON, R. (org) (1961) Histoire générale des sciences: La science antique et médievale — des origines a 1450. Paris: Quadrige/PUF.

VILAR, P. (1974) O ouro e a moeda na história. Lisboa: Publicações Europa-América. (s.d). 